\title{
How Green Manufacturing Likely to Replace Existing Methodologies
}

\author{
A. S. Elakkad \\ Designs and Production Department, \\ Faculty of Engineering, Ain Shams University \\ Cairo, Egypt
}

\begin{abstract}
This specific research paper tends to review the fact regarding how green manufacturing is likely to replace the current or existing methodologies in the industrial sector. On the introduction part, it highlights and explains several other survey works and contributions of outcomes which are associated to the modern state of the topic of green production as a trending factor to replace the current methodologies in manufacturing and production sector. Design and methodology used in the research study is encompassed in the literature review section to determine, categorize and briefly explain the main body of knowledge on green production and how it gradually taking the place of the old strategies used in the production and manufacturing sector; and convert this into an information which other researchers can easily access and make use of or to be used by any other interested party. Nonetheless, the Findings provided some level of knowledge on other unutilized topics associated with the issue of green manufacturing to enable further survey and exploration on the same. Moreover, this research paper tends to review the current literature on the topic under the survey and to try and address the gap in knowledge based on the matter.
\end{abstract}

Keywords- Green, manufacturing, competitive strategy, sustainability, environment

\section{INTRODUCTION}

Green is a term that has been used interchangeably over decades by researchers; some associate the term green to cover the concept of sustainability. This basically indicates the holistic view in regard to the environment, social, and political impact. The idea of green manufacturing is based on the assumption that successful financial benefits by any manufacturer can significantly rely on efficient consistency with environmental, ethical, and societal compliance. With many experts arguing that the whole idea is not about profit but enhancing ecological sustainability and cultural conservation [1]. For such reasons, most of the manufacturing industries have decided to go green in their production as a way of replacing the old methodologies of production [2].

Green manufacturing is currently gaining recognition from most manufacturers; the population grows, and the ecosystem and available resources seem to be experiencing undefined challenges, some of which are attributed to the manufacturing sectors. And most of the industries are definitely linked to the adverse environmental impacts such as global warming. This is a significant question that this particular paper tries to research on since many production industries are effectively embracing the issues of green production.
There is an urgent need for the community, individuals and manufacturers to effectively manage the available natural resources to enhance sustainability. As a repercussion, most governments throughout the world have officially enacted several environmental policies and favorable market in giving the industries that can provide green credentials. The green production is very useful and is gradually being embraced by many manufacturing industries, and this paper is aimed at finding out how green manufacturing is likely to replace the existing methodologies.

\section{LITERATURE REVIEW}

The manufacturers need to put into consideration the impact that is likely to be as a result of green manufacturing. The business of production should not be entirely relying on profit benefits but also ensuring that the environment and cultural activity surrounding the sector is sustained and conserved.

\section{A. Ways the Manufacturing Industry in Going Green}

Council (1996) reported that manufacturing is basically not perceived as environmentally or socially viable. However, the sector has drastically shifted to going green in many ways to ensure sustainability, healthier environment, and lower cost in the long run (Council, 1996). The manufacturing industry is going green through various techniques, as stated below.

\section{B. Minimizing waste}

According to [3], he observed that decrease, reuse, recycle are some of the strategies that have been embraced by manufacturers to promote the green movement. Most of the manufacturing industries tend to make effective utilization of the available raw resources without jeopardizing its environs. Nonetheless, Wassenhove seems to contradict the opinion by stating that older procedures have been very ineffective and inappropriate, resulting in more waste. For instance, wood product manufacturing has led to deforestation yet most of the wood is getting wasted as sawdust; therefore, the idea of reducing wastage via sawdust would initiate the factory to go green by use of some sustainable alternative product such as bamboo.

Again, some manufacturer seems to avoid overstocking to prevent wastage; especially, those materials that can quickly expire or lose value over time [3]. The industry will tend to venture into timely delivery of their raw material, and this can be facilitated by use of technology as opposed to older 
methodologies whereby the elements were just kept without proper storage or delivery timing.

\section{Recycling}

Most authors feel that various manufacturers are embracing recycling as one of the essential parts of their operations and production processes. With some of them using the waste products, the base of their final products. For example, old Newspapers can be used to make blankets. According to the environmental management literature, Green manufacturing is aiming majorly at production through process-oriented biological activities. The idea opts to enhance the sustainability of the environment via the final product made and the procedure involved.

\section{GREEN MANUFACTURING}

[4] suggested that the e-waste which appears to be a significant issue, green technology is the application of environmental science, environmental assessment and electronic appliances to assess, and preserve the natural environment and resources, and to prevent any sense of degrading effects of human engagement [4]. Green manufacturing can again be used to define sustainable energy generation technologies such as photovoltaic, wind turbines, Biofiltration, Bioremediation, Desalination, among other issues.

\section{SUSTAINABLE ENERGY GENERATION TECHNOLOGIES}

Many engineers and scientist have tried to come up with various designs of technologies and machines to enhance effectively shift to green manufacturing. There is the aim of strengthening the application of renewable energy since it is sustainable to development via its impact on human development and economic productivity. Figure 1 shows Energy Storage which is significant to a Reliable, Clean Electricity Supply that is renewable and environment friendly.

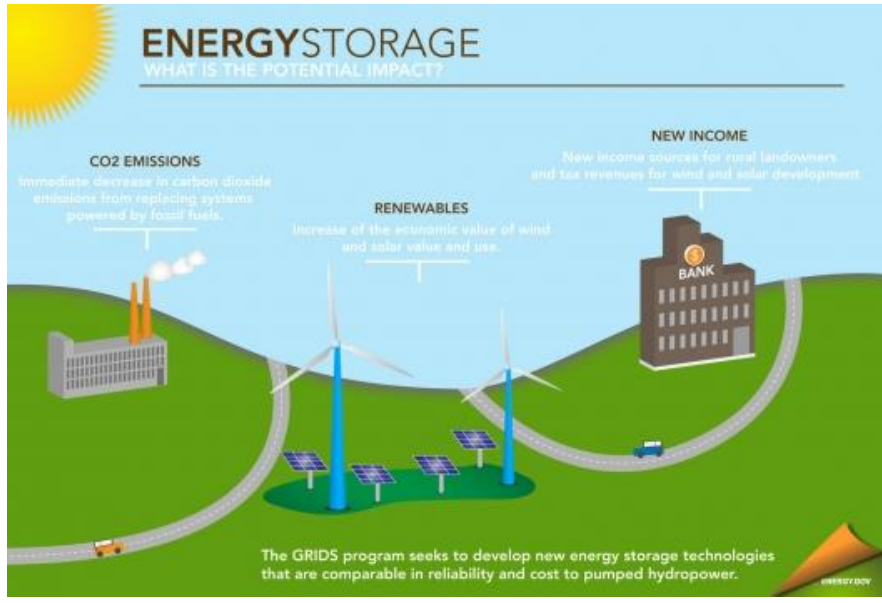

Fig. 1. Energy storage system (Source [5])

\section{SUSTAINABLE MANUFACTURING}

The idea of sustainability transpired from several reports and research and was significantly driven by environmental occurrences and catastrophe and the presumed deterioration and depletion of resources [6]. Sustainability, implicit an activity of analyzing and improving the environmental performance of manufacturing operations and systems. Assessing ecological and social performance indicates a challenging engineering and enterprise task. Sustainabilityassociated affects leads from activities which manufacturing processes and systems engage in resulting in final products.

\section{SUSTAINABLE GREEN OPERATIONS}

According to [7], suggested that sustainable green operations as an innovative environmental management strategy tend to promote the quality and environmental adherence of electronics manufacturers' inputs such as electronics and metals and outputs such as carbon emission. Green operations or manufacturing focus on product-and process-oriented environmental activities to balance and enhance financial performance as well as pollution minimization by considering the ecological effects in product design, packaging, and material application. Generally, it enhances recycling and reuse of product elements with ecodesign.

\section{EXPERIMENTAL DATA RESULTS}

The strategy was effective in assessment since it gave quantifiable and comprehensible results. From the data, 74\% of the expert participants reported being satisfied with the outcome of the green manufacturing as compared to the old existing methodologies. A proportion of dispensation presents the percentage of participants that are constituted within every classification. From the table, $72 \%$ of participants $(n=9)$ surveyed who took part in the research study reported being satisfied with the experience of the application of green manufacturing.

\section{TABLE I. A SAMPLE SIZE OF THE PARTICIPANTS AND THEIR} EXPERIENCE OF THE GREEN MANUFACTURING

\begin{tabular}{|c|c|}
\hline Gender & $\begin{array}{c}\text { Female=40\% } \\
\text { Male=60\% }\end{array}$ \\
\hline $\begin{array}{c}\text { Name of the industry } \\
\text { surveyed }\end{array}$ & $\begin{array}{c}\text { Macwright MES Ltd } \\
\text { Hydro Mechanical Services Ltd } \\
\text { Kamcan Plumbing \& Heating } \\
\text { KDR Plumbing And Heating }\end{array}$ \\
\hline $\begin{array}{c}\text { Satisfied with the green } \\
\text { manufacturing experience }\end{array}$ & $\begin{array}{c}\text { Very dissatisfied=1 } \\
\text { Dissatisfied }=\mathbf{2} \\
\text { Satisfied =6 }\end{array}$ \\
\hline \multicolumn{2}{|c|}{ a. Total sample size=9 } \\
\hline
\end{tabular}

\section{A. Effect of Green Manufacturing on Raw Material Cost}

Based on the survey, $73 \%$ of the mechanical experts seem to believe that green manufacturing is valid and is currently and gradually replacing the existing production strategies. Moreover, the participants emphasized that most manufacturing industries have minimized the cost that they incur in attaining the raw materials due to green manufacturing; most of the raw materials can be reused. Nonetheless, a relatively small number seemed to disagree, which constituted a total of $5 \%$ of the total number of participants felt that the cost of raw material due to green manufacturing was insignificant. $81 \%$ of the expert who was surveyed argued that some of the cost reduction was due to a decrease in energy-related costs such as the use of the solar panel. 


\section{B. Profit Margin and increase sales of the Industries Due to Green Manufacturing}

From the data analysis, it was evident that over $80 \%$ of the industries that were surveyed had asserted that they had doubled their profits as a result of embracing green technology. Many sectors feel that they have to spend a relatively lesser amount while using green manufacturing as compared to the use of the old methodology of product. The save the energy in production. Only $0.12 \%$ of participants felt that the profit margin had no significant difference.

\section{Tax Incentives}

Additionally, $97 \%$ of the surveyed industries that were embracing the green manufacturing and sustainable production seemed to have been benefited from various government incentives such as tax reduction on their industries. Such incentives have dramatically encouraged most of the industries to replace their old methodology of production with green manufacturing.

\section{CONCLUSION}

In summary, green manufacturing and production have tended to gain popularity among many states since the world wants to go green and apply renewable resources. The governments have assisted in several ways to promote green manufacturing through specific incentives such as enacting laws and cutting on the tax for the manufacturing industries that have gone green. The result was positive with over $82 \%$ of the participants agreeing that the green manufacturing is drastically replacing the old methodology. The green construction is much appropriated, and many researchers and engineers are still innovating on any possible technology to help promote the initiative of going green.

This research paper has clear introduced the topic under survey, and on the literature review section, some of the relevant ideas of the researcher have been highlighted. A quantitative research methodology was designed to help collect the required data for analysis, and finally, the conclusion drawn based on the findings of the research. The study will be found to be very relevant to the field of mechanical industries and some researchers can use the information to conduct further research on green manufacturing.

\section{REFERENCES}

[1] Alanne, K., \& Saari, A. (2006). Distributed energy generation and sustainable development. Renewable and Sustainable Energy Reviews, 10(6), 539-558. Retrieved from: https://econpapers.repec.org/RePEc:eee:rensus:v:10:y:2006:i:6:p:539558

[2] Bansal, P., \& Roth, K. (2000). Why companies go green: A model of ecological responsiveness. Academy of Management Journal, 43(4), 717-736. Retrieved from: https://journals.aom.org/doi/abs/10.5465/1556363

[3] Kleindorfer, P. R., Singhal, K., \& Van Wassenhove, L. N. (2005) Sustainable operations management. Production and Operations Management, 14(4), 482-492. Retrieved from: https://www.semanticscholar.org/.../Sustainable-OperationsManagement-Kleindorfer-Si.

[4] Dangelico, R. M., \& Pujari, D. (2010). Mainstreaming green product innovation: Why and how companies integrate environmental sustainability. Journal of Business Ethics, 95(3), 471-486. Retrieved from: https://www.jamk.fi/.../mainstreaming-green-productinnovation_dangelico-and-pujar.

[5] Dell, R. M., \& Rand, D. A. J. (2001). Energy storage-a key technology for global energy sustainability. Journal of power sources, 100(1-2), 2-17. Retrieved from:https://www.sciencedirect.com/journal/journal-of-powersources/vol/100/issue/1

[6] Kua, H. W., \& Lee, S. E. (2002). Demonstration intelligent building-a methodology for the promotion of total sustainability in the built environment. Building and Environment, 37(3), 231-240. Retrieved from:

https://www.researchgate.net/.../222004368_Demonstration_intelligent _building_-_A_m.

[7] Stock, T., \& Seliger, G. (2016). Opportunities of sustainable manufacturing in industry 4.0. Procedia Cirp, 40, 536-541. Retrieved from:

https://www.sciencedirect.com/science/article/pii/S221282711600144X 